\section{INCIDENCE OF CERVICAL ADENOCARCINOIMA: A RETROSPECTIVE CASE STUDY AT RIMS RANCHI}

KEY WORDS: Cervical

carcinoma, Cervical

Adenocarcinoma, Incidence, Younger population.

\section{Dr.Anshu}

Jamaiyar

\section{Dr. R.K. Singh}

\section{Dr. Sona Pathak*}

Associate Professor, Department of Pathology, Rajendra Institute of Medical Sciences, Ranchi.

Associate Professor, Department of Pathology, Rajendra Institute of Medical Sciences, Ranchi.

Junior Resident, Department of Pathology, Rajendra Institute of Medical Sciences, Ranchi. *Corresponding Author

BACKGROUND: Cervical cancer remains one of the most common causes of death for women globally and ranks 4 th of all cancers. Currently, every 2 minutes a life is lost to this disease. Endocervical adenocarcinomas are a heterogeneous group of neoplasms. Screening strategies designed for and effective in detecting squamous cell carcinoma precursors are less effective in detecting endocervical glandular precursor lesions. Because of this and possible other reasons, the real and relative incidence of endocervical adenocarcinoma has increased in recent years from $5 \%$ to up to $20-25 \%$, particularly in patients 30 yr of age or older. MATERIAL AND METHOD: It was a retrospective record based study, performed in the Department of pathology, RIMS Ranchi. Study population included all cases who were clinically suspected of any cervical pathology, with common clinical presentation of abnormal vaginal bleeding, intermenstrual heavy bleeding, postmenopausal bleeding, postcoital bleeding, whitish discharge per vagina, pain in lower abdomen, from January 2020- july 2021. RESULT: In our study incidence of SCC of cervix is $91.97 \%$ and second most common type is adenocarcinoma of cervix with incidence of $8.02 \%$. Striking feature of adenocarcinoma of cervix is its preponderance in younger female as compared to SCC.

\section{INTRODUCTION:}

Cervical cancer remains one of the most common causes of death for women globally and ranks 4 th of all cancers. Currently, every 2 minutes a life is lost to this disease. Importantly, it is the leading cause of cancer deaths in women in 42 countries. ${ }^{1}$ In 2020, the global mortality statistics increased to over 340000 women and these are likely to continue to grow, particularly in underprivileged and vulnerable communities.

The global cervical cancer burden is disproportionally high in low and middle-income countries, where $83 \%$ of all new cases and $85 \%$ of cervical cancer deaths occur. ${ }^{2}$ India accounts for nearly one-fourth of the world's cervical cancer deaths, with 60,078 deaths and 96,922 new cases in 2018..$^{3-4}$ This largely preventable disease is the second most common cause of cancer mortality among Indian women ${ }^{5}$. It is the one of the leading cause of cancer mortality, accounting for $17 \%$ of all cancer deaths among women aged between 30 and 69 years. It is estimated that cervical cancer will occur in approximately 1 in 53 Indian women during their lifetime compared with 1 in 100 women in more developed regions of the world. ${ }^{6}$

Through Human Papilloma Virus (HPV) vaccination and screening campaigns, higher income countries have successfully reduced their burden of cervical cancer by as much as $65 \%$ over four decades ${ }^{7}$. The average age of patients with invasive cervical carcinoma is between 45 and 50 years. Squamous cell carcinoma is the most common histologic subtype, accounting for approximately $80 \%$ of cases. The second most common type of tumor is adenocarcinoma, which constitutes about $15 \%$ of cervical cancer cases and develops from a precursor lesion called adenocarcinoma in situ. Adenosquamous and neuroendocrine carcinomas are rare cervical tumors that account for the remaining $5 \%$ of the cases. All of the above mentioned tumors are caused by high risk HPVs( Human papilloma virus) ${ }^{8}$.

Endocervical adenocarcinomas are a heterogeneous group of neoplasms. Screening strategies designed for and effective in detecting squamous cell carcinoma precursors are less effective in detecting endocervical glandular precursor lesions. Because of this and possible other reasons, the real and relative incidence of endocervical adenocarcinoma has increased in recent years from $5 \%$ to up to $20-25 \%$, particularly in patients $30 \mathrm{yr}$ of age or older, according to studies from the United States and Europe ${ }^{9-12}$. Most endocervical adenocarcinomas are associated with high-risk oncogenic human papillomavirus (HPV) most commonly HPV 18,16 , and 45 5-7. Unlike squamous cell carcinoma of the cervix, however, approximately $15 \%$ of all endocervical adenocarcinomas are not associated with HPV (HPVindependent) and harbor distinct molecular alterations. ${ }^{13}$

Aim of our present study is to evaluate the incidence of spectrum of cervical carcinoma specially adenocarcinoma in the patients attending RIMS, Ranchi with various cervical pathology.

\section{MATERIALS AND METHOD:}

It was a retrospective record based study, performed in the Department of pathology, RIMS Ranchi. Study population included all cases who were clinically suspected of any cervical pathology, with common clinical presentation of abnormal vaginal bleeding, intermenstrual heavy bleeding, postmenopausal bleeding, postcoital bleeding, whitish discharge per vagina, pain in lower abdomen, from January 2020- july 2021 . All the cervical biopsy specimen were routinely processed as per standard protocol to obtain tissue paraffin blocks, then sections were taken and stained by hematoxylin and eosin stain. Detailed microscopic evaluation was done and diagnosis was given as per WHO classification. Study procedure involves case reports having patients age and clinical symptoms. The epidemiological data of cervical carcinoma were compared and analysed.

\section{RESULT AND DISCUSSION:}

In our present study 226 cases were included with various cervical pathology attended in RIMS, with some common complaints of abnormal vaginal bleeding, intermenstrual heavy bleeding, postmenopausal bleeding, postcoital bleeding, whitish discharge per vagina, pain in lower abdomen, and detailed histopathological study were performed from the biopsy specimen of cervix. Among the spectrum of cervical pathology, 149(65.9\%) were diagnosed with squamous cell carcinoma and $13(5.7 \%)$ cases with adenocarcinoma of cervix. (Table-1) Accounting all the 
cervical carcinomas SCC contributes $91.97 \%$ and adenocarcinoma $8.02 \%$.(Pie chart-1). No other carcinomas were detected which are very rare like adenosquamous and small cell carcinoma of cervix.

In our study analysis it has been seen that incidence of SCC most commonly occurs in $51-60$ years age group (32.21\%) followed by $41-50$ years $(25.5 \%)$. Whereas incidence of adenocarcinoma occurs most commonly in age group of 41 50 years $(30.76 \%)$ followed by $31-40$ years $(23.07 \%)$. [Table2]

Anton-Culver et al. ${ }^{14}$ also reported similar findings of incidence of adenocarcinoma of cervix in younger age group compared to SCC of cervix. Simona Stolnicu et al. ${ }^{15}$ reported that adenocarcinoma of cervix is the second most common type of cervical carcinoma and its incidence are in increasing trend in recent years from $5 \%$ to up to $20-25 \%$, particularly in patients $30 \mathrm{yr}$ of age or older i.e younger age group. Our study also shows similar findings.

Disease wise incidence( table-1)

\begin{tabular}{|l|l|l|}
\hline DISEASE & $\begin{array}{l}\text { NUMBER OF } \\
\text { CASES }\end{array}$ & PERCENTAGE \% \\
\hline $\begin{array}{l}\text { Squamous cell } \\
\text { carcinoma }\end{array}$ & 149 & 65.9 \\
\hline Adenocarcinoma & 13 & 5.7 \\
\hline Dysplastic changes & 19 & 8.4 \\
\hline Endocervical polyp & 19 & 8.4 \\
\hline $\begin{array}{l}\text { Endocervical polyp } \\
\text { with dysplastic changes }\end{array}$ & 2 & 0.9 \\
\hline Chronic cervicitis & 24 & 10.6 \\
\hline Total & 226 & 100 \\
\hline
\end{tabular}

Incidence of carcinoma cervix (chart-1):

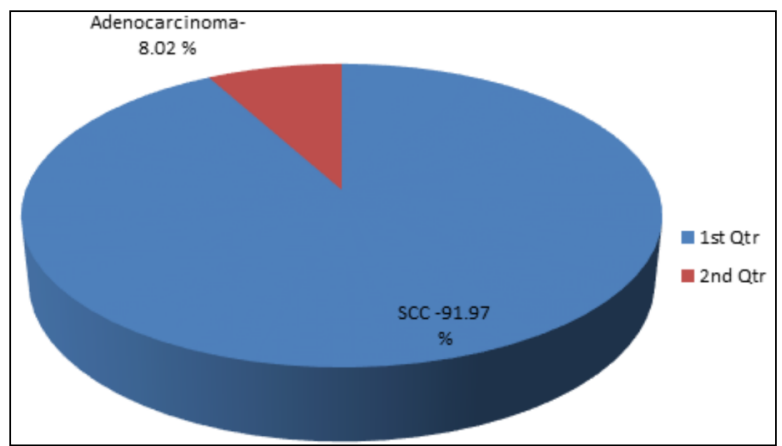

Age wise incidence of cervical carcinoma( table-2):

\begin{tabular}{|l|l|l|l|l|}
\hline $\begin{array}{l}\text { Age group } \\
\text { (in years) }\end{array}$ & $\begin{array}{l}\text { SCC } \\
\text { Cases }\end{array}$ & $\begin{array}{l}\text { Percentage } \\
\% \text { of SCC }\end{array}$ & $\begin{array}{l}\text { Adenocarcino } \\
\text { ma cases }\end{array}$ & $\begin{array}{l}\text { Percentage } \\
\% \text { of cases }\end{array}$ \\
\hline$<30$ & 1 & 0.67 & 2 & 15.38 \\
\hline $31-40$ & 23 & 15.4 & 3 & 23.07 \\
\hline $41-50$ & 38 & 25.5 & 4 & 30.76 \\
\hline $51-60$ & 48 & 32.21 & 2 & 15.38 \\
\hline $61-70$ & 27 & 18.12 & 1 & 7.69 \\
\hline$>70$ & 12 & 8.0 & 1 & 7.69 \\
\hline Total & 149 & 100 & 13 & 100 \\
\hline
\end{tabular}

\section{CONCLUSION:}

In our study incidence of SCC of cervix is $91.97 \%$ and second most common type is adenocarcinoma of cervix with incidence of $8.02 \%$. Striking feature of adenocarcinoma of cervix is its preponderance in younger female as compared to SCC.

\section{REFERENCES:}

1. Beddoe A. M. (2019). Elimination of cervical cancer: challenges for developing countries. Ecancermedicalscience, 13, 975. https://doi.org/ 10.3332/ ecancer.2019.975

2. Ali F, Kuelker R, Wassie B. Understanding cervical cancer in the context of developing countries. Ann Trop Med Public Health. 2012;5(1):3.DOI: https:// doi.org/10.4103/1755-6783.92871
3. Ferlay J, Soerjomataram I, Dikshit R, et al. Cancer incidence and mortality worldwide: sources, methods and major patterns in GLOBOCAN 2012. Int J Cancer 2015;136(5):E359-386.DOI:https://doi.org/10.1002/ijc.29210

4. Bruni L, Albero G, Serrano B, et al. Human Papillomavirus and Related Diseases Report. Information Centre on HPV and Cancer (HPV Information Centre);2019.

5. Kadam Y,Dhobale R, Gore A,Tripathi N. Barriers for early detection of cancer amongst Indian rural women. South Asian J Cancer. 2014; 3(2): 122. DOI: https://doi.org/10.4103/2278-330X.130449

6. Institute for Health Metrics and Evaluation. The Challenge Ahead: Progress in Breast and Cervical Cancer. Institute of Health Metrics and Evaluation. 2011. [Last accessed on 2016 Jan 21]. Available from: http:// www. healt hmetrics andevaluation.org/publications/policyreport/challenge-ahead-progressand-setbacksbreastand-cervical-cancer

7. Jemal A, Center MM, DeSantis C, Ward EM. Global Patterns of Cancer Incidence and Mortality Rates and Trends. Cancer Epidemiol Biomarkers Prev. 2010; 19(8): 1893-1907. DOI: https://doi. org/10.1158/1055-9965.EPI10-0437

8. Manoj K. S, Vinay K.,Cervical carcinoma. Robbins and Cotran. Pathologic basis of disease tenth edition, volume 2,(998)

9. Wang SS, Sherman ME, Hildesheim A, et al. Cervical adenocarcinoma and squamous cell carcinoma incidence trends among white women and black women in United States for 1976-2000. Cancer 2004;100:1035-44.

10. Smith HO, Tiffany MF, Qualls CR, et al. The rising incidence of adenocarcinoma relative to squamous cell carcinoma of the uterine cervix in the United States-a 24-year population based-study. Gynecol Oncol 2000;78:97-105.

11. Baldur-Felskov B, Munk C, Nielsen TSS, et al. Trends in the incidence of cervical cancer and severe precancerous lesions in Denmark, 1997-2012. Cancer Causes Control 2015;26:1 105-16.

12. van der Horst J, Siebers AG, Bulten J, et al. Increasing incidence of invasive and in situ cervical adenocarcinoma in the Netherlards during 2004-2013. Cancer Med 2017:6:416-23.

13. Houghton O, Jamison J, Wilson R, et al. pl6 immunoreactivity in unusual types of cervical adenocarcinoma does not reflect human papillomavirus infection. Histopathology 2010;57:342-50.

14. Anton-Culver, H., Bloss, J. D., Bringman, D., Lee-Feldstein, A., DiSaia, P., \& Manetta, A. (1992). Comparison of adenocarcinoma and squamous cell carcinoma of the uterine cervix: a population-based epidemiologic study. American journal of obstetrics and gynecology, 166(5), 1507-1514. American journal of obstetrics and gynecolo

15. Stolnicu, S., Park, K.J., Kiyokawa,T., Oliva, E., McCluggage,W. G., \& Soslow, R.A. (2021). Tumor Typing of Endocervical Adenocarcinoma: Contemporary Review and Recommendations From the International Society of Gynecological Pathologists. International journal of gynecological pathology : official journal of the International Society of Gynecological Pathologists, 40(Suppl 1), S75-S91.https:// doi.org/ 10.1097/ PGP. 00000000 00000751 